\title{
NOTICIARIO/NEWS
}

\section{CENTRO BRASILEIRO DE CLASSIFICAÇÃO DE DOENÇAS}

Em julho de 1976 foi firmado convênio entre o Ministério da Saúde, Organização Panamericana da Saúde e a Universidade de São Paulo visando a criação do "Centro Brasileiro de Classificação de Doenças", o qual passou a funcionar na Faculdade de Saúde Pública da USP, junto ao Departamento de Epidemiologia.

A 29." Assembléia Mundial da Saúde, realizada em maio de 1976 , em sua $12 .^{\text {a }}$ sessão plenária $(12 / 5 / 76)$, considerando o interesse dos países de língua portuguesa na criação de um centro internacional, nessa língua, para a Classificação Internacional de Doenças (CID), semelhante aos existentes em lingua inglesa, francesa, russa e espanhola e levando em conta a implantação, em futuro próximo, de um centro brasileiro para a tradução e a aplicação da CID em língua portuguesa, na Universidade de São Paulo, recomendou:

1. que o Centro Brasileiro, na Universidade de São Paulo, fosse reconhecido pela OMS como um centro para a Classificação Internacional de Doença em língua portuguesa;

2. que fossem estabelecidas ligação e colaboração entre esse centro e os países de língua portuguesa; e

3. que a OMS desse o apoio técnico necessário ao centro e aos países de língua portuguesa para a tra- dução, nesse idioma, da 9." Revisão da CID e de suas classificações suplementares, a fim de que pudessem ser utilizadas com igual eficácia em todos os países de idioma português.

As funções e atividades do novo Centro serão semelhantes àquelas exercidas pelos quatro outros centros internacionais já existentes (Londres, Paris, Moscou e Caracas) e que podem ser resumidas nas srguintes:

- estudar os problemas relativos à estrutura, interpretação e aplicação da CID e suas classificações suplementares;

- assessorar a OMS nas atividades relacionadas à promoção $\mathrm{e}$ às revisões da CID;

- promover a melhoria da qualidade das informações dos atestados de óbitos;

- promover em conjunto com as entidades interessadas o treinamento de pessoal, em diferentes níveis, no uso da CID;

- atuar como centro de referência;

- preparar a edição, em língua portuguesa, das sucessivas revisóes;

- divulgar publicações de interesse dos usuários da CID e colaborar e assessorar pesquisas que envolvam o uso da mesma.

\section{NOVO MODELO DE DECLARAÇÃO DE OBITO}

Com o objetivo de melhorar as informaçōes sobre mortalidade em todo o território nacional, foi adotado, pelo Ministério da Saúde, um novo modelo de $D e-$ claração de óbito que, até dezembro de 1976, deverá estar implantado em todos os Estados.

O modelo é semelhante aos existentes 
em vários países do mundo, inclusive latino-americanos. Uma das grandes vantagens de sua adoção, entre nós, é a padronização para todo o País, visto que cada Estado apresentava um modelo próprio e, algumas vezes, num mesmo Estado havia vários.

A nova Declaração de Óbito mantém a mesma forma para o "Atestado Médico" (dividida em partes I e II) adotada internacionalmente por recomendação da OMS desde 1950. Por outro lado, foi bastante reformulada a parte referente à identificação introduzindo-se variáveis importantes para vários tipos de análises.
O mesmo formulário é usado para Declaração de óbito e Declaração de Óbito Fetal. Para os óbitos de menores de um ano de idade o formulário apresenta a possibilidade de registrar dados de importância, tais como: idade da mãe e peso ao nascer para os óbitos de menores de 28 dias.

Concomitantemente à distribuição da nova Declaração de Óbito em todo o País, o Ministério está distribuindo o "Manual de Instruções Para o Preenchimento da Declaração de Óbito" o qual, de maneira clara e simples, orienta o médico no preenchimento dos diferentes itens, incluindo alguns exemplos com histórias clínicas. 
6 ESTADO CIVIL OESQUITADO [] OUTRO $\square$ IGNORADO $\square]$ FEMIN $\square$

10 LOCAL DE ocorréncia

I D A DE

FILIA. 19 NOME DO PA

CÃO

PAI

21 OCUPACĀO HABITUAL

23 OCUPACAO HABITUAL

32 RECEBEU ASSISTÉNCIA MÉdICA DURANTE A 33 O MÉdICO QUE ASSINA ATENDEU AO DOENCYA QUE OCASIONOU A MORTE

causa da morte. ianote so um diagnositco for lintig

PARTE - 1

DOENCA OU ESTADO MORBIDO QUE CAUSOU DRRETA al

MENIE A MORTE

CAUSAS ANTECEDENTES

ESTADOS MORBIDOS. SE EXISTIREM, QUE PRODUZIRAM

a causa acima registradi. MENCIONANDOSE EM

ULTIMO IUGAR a CAUSA bASICA

36 PARTE -. II

OUTROS ESTADOS PATOLOGICOS SUNIILAIIVISG

QUE CONTRIBUIRAM PARA A MORIT. POREM TAAOO

RELACIONADOS COM A DOENCA. OU ESTADO

patologico que a hrodULIU

NOME DO MEOICO 


\section{DEFINIÇÕES}

(De acordo com a CLASSIFICAÇÃO INTERNACIONAL DE DOENÇAS - REVISÃO 1965)

\section{NASCIMENTO VIVO}

Nascimento vivo é a expulsão ou extração completa de um produto de concepcão do corpo materno. independentemente duraçāo da gravidez, o qual, depcıs da separação. respire ou de qualquer outro sınal de vida, tal como batimentos do coraçã pulsaçōes do cordão umbilical ou movimentos efetivos dos músculos de contração voluntária, estando ou não cortado o cord umbilical e estando ou não desprendida a placenta. Cada produto de um nascimento que reuna essas condiçōes se conside como uma criança nascida viva.

\section{OBITO FETAL}

Obito tetal é a morte de um produto da concepção, antes da expulsão ou de sua extração completa do corpo materno. ind pendentemente da duraçāo da gravidez; indica o óbito o tato de, depois da separação, o feto nāo respirar nem dar nenhu outro sinal de vida, como batimentos do coraçāo, pulsações do cordāo umbilical ou movimentos efetivos dos músculos de co tracão voluntária

\section{CAUSAS DE MORTE}

As causas de morte a serem registradas no Atestado Médico de causa de morte, são todas aquelas doenças, estados mórbıd ou lesōes que produziram a morte, ou que contribuiram para ela e as circunstancias do acidente, ou da violencia que prod ziram essas lesōes.

\section{CAUSA BÁSICA DE MORTE}

Define-se como causa básica de morte: (a) a doença ou lesão que iniciou a cadeia de acontecimentos patológicos que conduzira diretamente à morte, ou: (b) as circunstáncias do acidente ou violencia que produziram a lesão fatal.

\section{NAASCTDO MORTO OU "NATHAOTIO}

"Nascido morto ou natımorto" é o óbito fetal tardio ou seja o óbito ocorrido antes da expulsäo ou extração completa do cor materno, de um produto da concepção que tenha alcançado 28 semanas completas ou mais de gestação.

\section{LEG ISLAÇĀO}

(Lei n.0 6.015, de 31 de dezembro de 1973 com as corrigendas da Lei n.0 6.126, de 30 de junho de 1975)

\section{CAPITULO IX}

\section{DO ÓBITO}

Art. 77. Nenhum sepultamento será feito sem certıdão de oficial de regıstro do lugar do falecimento, extraida após a lavratu do assento de óbito, em vista do atestado de médico, se houver no lugar, ou, em caso contrário, de duas pessoas qualificad que tiverem presenciado ou verificado a morte

9 $1^{\circ}$ ) Antes de proceder ao assento de obito de criança de menos de 1 ano, o oficial verificará se houve registro de nas mento que, em caso de falta, será previamente telto.

$92^{\circ}$ ) A cremaçăo de cadáver somente será telta daquele que houver manifestado a vontade de ser incinerado ou no interes da saude pública e se o atestado de obito houver sido firmado por 2 (dois) médicos ou por 1 (um) médico legista, no ca de morte violenta. depois de autorizada pela autoridade judiciária. 